\title{
Husserlian Descriptive Phenomenology: A review of intentionality, reduction and the natural attitude
}

\author{
Martin Christensen ${ }^{* 1}$, Anthony Welch ${ }^{2}$, Jennie Barr ${ }^{2}$ \\ ${ }^{1}$ School of Nursing, Queensland University of Technology, Brisbane, Australia \\ ${ }^{2}$ School of Nursing \& Midwifery, Central Queensland University, Queensland, Australia
}

Received: February 4, 2017

DOI: $10.5430 /$ jnep.v7n8p113
Accepted: February 28, 2017

Online Published: March 26, 2017

\begin{abstract}
Background and aim: Descriptive phenomenology is widely used in social science research as a method to explore and describe the lived experience of individuals. It is a philosophy and a scientific method and has undertaken many variations as it has moved from the original European movement to include the American movement. The aim of this paper is to describe descriptive phenomenology in the tradition of Edmund Husserl. Integrative literature discussing the nature of descriptive phenomenology was used within this paper to elucidate the core fundamental principles of Husserlian descriptive phenomenology.

Methods: This is a methodology paper that provides both an overview of the historical context and the development of descriptive phenomenology in the tradition of Husserl.

Results and discussion: Descriptive phenomenology is explained from its historical underpinnings. The principles of the natural attitude, intentionality and the phenomenological reduction are described and using practical examples illustrate how each of these principles are applied within a research context.

Conclusions: Understanding the key philosophical foundations of Husserlian descriptive phenomenology as a research method can be daunting to the uninitiated. This paper adds to the discussion around descriptive phenomenology and will assist and inform readers in understanding its key features as a research method.
\end{abstract}

Key Words: Husserl, Phenomenology, Descriptive phenomenology

\section{INTRODUCTION}

It is often recognised that Husserl is the founder of the phenomenological movement. ${ }^{[1]}$ Indeed phenomenology as a research process was developed by Husserl in an attempt to define a philosophical method, different to the natural sciences, which would provide insight into the experiences of conscious objects. Originally describe from the Greek word 'phainein', phenomenological philosophy itself emphasises the attempt to get to the truth of matters, to describe phenomenon in the manner in which it appears, that is as it manifests itself to consciousness of the experiencer. ${ }^{[2]}$ For example, human conscious experiences are experiences of the world and it is the world that gives meaning to these experiences. Moreover, the methods of phenomenological inquiry seek to articulate the meaning of experienced phenomena, 'to go to the things themselves', rather than measure them. ${ }^{[2]}$ Yet more importantly there is an element of naivety when describing the things themselves otherwise there is the potential for simply asserting what "we" [the researcher] already understood of the experience. The phenomenological inquiry

\footnotetext{
* Correspondence: Martin Christensen; Email: martin.christensen@qut.edu.au; Address: School of Nursing, Queensland University of Technology, Brisbane, Australia.
} 
can be considered a source of evidence beyond existing understanding and as such provide deeper more meaningful productive insights. ${ }^{[3]}$

\section{Descriptive Phenomenology-an OVERVIEW OF THE ORIGINS AND UNDER- PINNING PHILOSOPHY}

Phenomenology has a long history and not necessarily as a recognised philosophy or a methodology as it is perceived today. Instead its first uses were applied more within the context of intentionality; intentionality in this case to mean the human minds ability to refer to objects outside of itself. Aristotelian thought regarding perception appeared to focus on the minds awareness of objects without distinguishing the objects matter. ${ }^{[4]}$ Aristotle argued that objects presented to the mind were senses of the object which was distinctly different from its matter. ${ }^{[5]}$ Sajama and Kamppinen use an example of a tree to illustrate this point:

“... when I see a tree, my mind receives the form of the tree into itself but it does not receive the wooden substance... there is similarity in form between the tree that grows in the yard and my mental picture of it, but there is no similarity between them as regard to matter."

This then led to the notion that there were two spheres or forms of existence: intentionality and reality. The former as a conscious psychical form while the latter a combination of form and matter existing in the real world. For Aristotle "all things that are thought about must exist in order that they may be thought about". [5] The ancient sceptics also cast doubt as to the formation of mental pictures and as to whether they exist outside of the mind or are the objects of the external world really only our own perceived mental pictures. In other words, when an object such as a tree appears before the mind we take for granted that it exists intentionally and do not doubt its appearance, but moreover we become more concerned by the account given of its appearance, which is entirely different from questioning its appearance. ${ }^{[6]}$

Equally, it was in Summa Theologica that St. Thomas Aquinas made the distinction between intentionality and reality clearer:

"Just as a house has being more nobly in the mind of the artificer than in matter, but nevertheless 'house' is said more truly of that which is in matter than that which is in the mind because the former is a house in act, while the latter is a house in potency."[7]
While the medieval scholastics regarded the two forms as being different, others used this inequality, rightly or wrongly, when attempting to define the existence of God. For example using the premise that something that can be thought surely must exist in the mind and conversely something that cannot be thought cannot not exist in the mind, means that God must exist because on hearing the name God an individual is able to form a mental picture of God and as such because it can be thought it must exist in reality. ${ }^{[8]}$ Clearly this is a flawed argument, as Aquinas argued not everyone will have a similar understanding of the 'word' God and therefore thinking of God in this sense does not necessarily follow that God exists in reality, but only in intellect. ${ }^{[5]}$

The notion of intentionality (phenomenology) seemed to lose impetus over this period of time. It appeared in the writings of Descartes, Kant, Hegel and Hume, ${ }^{[9]}$ but wasn't until the mid-19th century when Brentano, who was influenced by the medieval scholastics, commenced a revival of intentionality especially the notion of immanent objectivity and intentional inexistence. Considered to be the first real phenomenologist, he set about developing a scientific psychology which would challenge the well-established natural sciences with a science which investigated mental phenomena. In describing intentionality, Brentano aimed to describe mental phenomena as they appeared to the person "in themselves only from within" - in other words the fundamental law of a priori of the mental. ${ }^{[10]}$ However, for Brentano in order for the a priori to be present it had to ascribe to three central tenents: content relationship (presentation), the mental direction towards an object (judgement) and immanence of the object (motion). As a result these mental phenomena were experiences which an individual lives through - what is really presented to the mind; for example the idea of death as opposed to death itself or seeing something red as a presentation of red. ${ }^{[10,11]}$

Brentano's General Psychological Theory held that there exists qualitative differences between physical and mental phenomena $^{[12]}$ - a form of Cartesian dualism which held that "all the appearances of our consciousness are divided into two great classes - the class of physical and the class of mental phenomena". ${ }^{[10]}$ In this case the former are considered objects as they are presented to consciousness. The latter are acts that contain objects as they appear, for example admiring a sunset or hearing music. It is immediately evident that the mental act of admiring a sunset or hearing music "has become a memory, replaced in immediate consciousness by the new mental act of remembering". ${ }^{[12]}$ This was an important consideration for Brentano, because he believed conscious attention to the act altered its nature. In other words, an individual can consciously question the reality of the object but not the act of thinking because this is 
reliant on what Brentano considered mental acts to contain - a primary and a secondary object. The primary object is that object which is immediately observed in consciousness, an immanent objectivity. Whereas the secondary object is unconsciously perceived only to be re-lived when brought to consciousness and as a result becomes a new mental act. Take sadness, for example. When in a saddened state (the primary object), a person does not consciously think they are sad or begin to conceive the mental act of sadness (the secondary object). Instead, it is once the sadness has dissipated that conscious thought of being sad (the act) can be observed and as a result the act has now changed. Brentano considered this the absolute reality of mental phenomena, which was loosely based around Descartes cogito ergo sum (I think therefore I am).

Husserlian intentionality expanded on this premise by suggesting that intentionality for the 'naïve man' (sic) has an inner and outer perception (physical and mental phenomena), one in which there is a distinction between the perception of external objects and the perception of self. ${ }^{[13]}$ There are echoes of Cartesian dualism like Brentano, yet Husserl, saw the difference between the two types of perception in the way they arise in consciousness. External perception for example is formed from the sense organs whereas reflection forms the inner perception, both of which form phenomena given through appearances, but importantly appearances of something. For Husserl it was this approach that enabled him to give meaning to the natural attitude and therefore develop an epistemological understanding of the intentional relationship of everyday lives - in other words the 'life-world' ${ }^{[14]}$

\section{HuSSERlian DESCRIPTIVE PHENOMENO- LOGICAL PHILOSOPHY}

The philosophical underpinnings of Husserlain phenomenology are that of the lived, human experience and as such he sought to reinstate the human world as a foundation of science that brought justice to the everyday lived experience - the going to the things themselves. ${ }^{[15]}$ Moreover, the rich and complex source of unspoken meaning associated with being and experiencing shapes an individual's understanding of their life-world.

\subsection{The natural attitude}

Described by Husserl as the "natural attitude" (standpoint), experience occurs within the context of the world the individual is engaged with. This engagement is often taken for granted and becomes an absorbing, self-immersed collection of happenings that are implicitly understood without a conscious response. ${ }^{[15]}$ Using Plato's allegory of the cave as described by Bossert ${ }^{[16]}$ puts into context at least the analogy

Published by Sciedu Press of dimensionality which Husserl spoke of that is integral to understanding the natural attitude. Plato's cave dwellers are men who have been imprisoned since childhood. They are shackled in such a way that they can neither move their legs nor head and as such can only look straight ahead at a wall. Some distance behind them a fire is burning and between the prisoners and the fire is a road along which men carry an assortment of objects that cast shadows on the wall in front of the prisoners. The noise created by the 'road-men' is reflected off the wall unto which the prisoners falsely believe is coming from the shadows. It is the shadows and the noises that emanate from them that are the prisoners' sense of reality. ${ }^{[16]}$ In other words, individuals such as the cave dwellers live their everyday lives based on a multitude of metaphysical assumptions that are formed from their knowledge and experiences about the existence of objects and the world - in this case silhouettes. ${ }^{[17]}$ This is made possible because pre-reflectively individuals are similar to the cave dwellers in that engagement with the world is a collection of happenings and existential assumptions that some might say is an illusion of the truth. From a Husserlian perspective the notion of the natural attitude is one comprised of a naivete of experience or common sense everyday reality with the added belief in the existence of an external material reality, one in which there is a straight forward acceptance of experience and knowledge. ${ }^{[17]}$ To give another example; Dreyfus ${ }^{[18]}$ likens the natural attitude to opening a door - one simply depresses the door handle and enters the room, there is not a conscious reflective thought as to the action - it is simply opening the door.

In addition, Husserl has suggested that the natural attitude is also a collection of self-effused opinions that, whilst not claiming to be the absolute truth, do form doxic beliefs that also view and engage with entities and/or objects in an absoluteness of understanding. ${ }^{[19]}$ For example, when taking a patient's blood pressure using an electronic blood pressure machine the nurse does not need to know the intricate mechanical and electrical workings or algorithms the machine uses to measure and report the blood pressure. He/she presses a button and is then reliant on the assumption that the machine will 'normally' produce the measured blood pressure reading. It is these former beliefs about the machine workings which are doxai beliefs and as such also form part of the naivety of daily life: I turn the key in my car, knowing it will start the engine; I don't need to know how or why, simply that it does.

This culminates in a 'taken for grantedness' or 'casualness' around the nature of conscious experience, one in which Dalberg et al. ${ }^{[15]}$ describes as: 
“... the everyday immersion in one's existence and experience in which we take for granted that the world is as we perceive it."

It is this existence that Dahlberg et al. ${ }^{[15]}$ aptly described above, that Husserl refers to as the "General Thesis of the Natural Attitude", which in very simplistic terms suggests the world exists or the world is, it is always there in reality. ${ }^{[20]}$ What is important to note that the 'world', this ontological realism, is made up of not only external objects such as trees, rivers, and mountain ranges (the macrophysical) but also the microphysical - judging, dreaming and desiring. To quote Husserl:

"I am conscious of a world endlessly spread out in space, endlessly becoming and having endlessly become in time. I am conscious of it: that signifies, above all, that intuitively I find it immediately, that I experience it. By my seeing, touching, hearing, and so forth, and in the different modes of sensuous perception, corporeal physical things with some spatial distribution or other are simply there for me, "on hand" in the literal or the figurative sense, whether or not I am particularly heedful of them and busied with them in my considering, thinking, feeling, or willing. Animate beings too - human beings, let us say - are immediately there for me: I look up; I see them; I hear their approach; I grasp their hands; talking with them I understand immediately what they mean and think, what feelings stir within them, what they wish or will.,"[21]

This positing of the world as the domain of the real was fundamental for Husserl in explaining the waking experiences that individuals encounter in the world. ${ }^{[22]}$ However there is a vagueness and uncriticalness that surrounds the natural attitude especially in attempting to define and explain phenomena from and within the life-world from a scientific perspective. It was here that Husserl attempted to explain the natural attitude in terms of an individual's interaction with their life world - he referred to this as intentionality.

\subsection{Intentionality}

Originally conceived from Brentano who in turn developed the work from middle ages scholastic philosophy, intentionality espouses the individual to become 'intentional' (psychical) with the world, for example when they experience something, that experience has meaning, it has an 'aboutness'. In other words as Moran ${ }^{[2]}$ suggests "every act of loving is a loving of something, every act of seeing is about seeing of something”. For Brentano intentionality involves two things within higher cognition:

(1) The aboutness or directedness towards an object;

(2) The internal (mental) existence of the object.

Here he makes the distinction that the world in its entirety is comprised of two great classes - physical and mental phenomena. He defines the physical as the outer perception which involves experiences from the bodily sense-organs - seeing, hearing, feeling, taste and smell (sense datum), whereas the inner perception is associated with the almost intuitive, reflexivity of consciousness of the physical world such as judging, knowing, desiring and imagining. ${ }^{[1]}$ Moreover, it was this inner perception that Brentano was also interested in by discovering the characteristics of psychical phenomena, for example the relation between the intramental (immanent) object and the intra-mental act of the presented object from an ontological perspective - what is known by the knower. ${ }^{[23]}$

While Husserl was in agreeance with Brentano's notion of intentionality encompassing an aboutness or directedness of consciousness towards an object (the noema), he disagreed with the idea that intentionality was 'purely' mentalistic. He was not interested in neuro-physiology, but the epistemology of experience and perception, for example what does it mean to imagine dying. ${ }^{[24]} \mathrm{He}$ understood intentionality to objectify the function of the mental act, that is to draw a distinction between the intended object and object intended. While recognising that the object in question may or may not exist, Husserl accepted that the extra-mental perceptions of the physical world also serve as a direction for the analysis of the intentional act. In other words, although the objective nature of the intentional act may not entirely exist concretely, it has meaning and with it a sense of being in an individual's consciousness that forms understanding and experience within their own unique life-world. ${ }^{[25]}$ Instead Husserl no longer viewed intentionality as a relationship between an intra-mental act to its mental object, but an individual's knowledge, experience and perceptions of the world as a comprehensive intentional object. ${ }^{[26]}$ However, it must be remembered that the intentional relation is not one based on causality. Because something exists in the physical world and perceived by an individual's outer perception does not necessarily imply that changes in the mental will occur or a relation between the knower and what is known will develop. On the contrary, it is the nature of the act that defines action towards the object; what Husserl refers to as transcendence. $^{[27]}$

From a phenomenological perspective, intentionality for Husserl, as already mentioned, is consciousness of some- 
thing as something. It is here that he makes the distinction between the 'of' (noesis) and the 'something' (noema). Referring to this as noesis and noema, Husserl attempted to differentiate the conscious directedness towards something (the of) and the characteristics of the 'act' of consciousness (the something) associated with the object. For example, when one considers the most iconic figure in nursing, it is immediately apparent that the person in question is Florence Nightingale. ${ }^{[27]}$ Noetically the object which is being perceived is the person who transformed or legitimised nursing, that is to say it is the only view within a specific time frame of the object which has meaning and/or symbolism. Over time recalling the act of meaning may become different, but simultaneously becoming aware that what was meant and viewed on those past occasions and what is meant and viewed in the present is the same (noema). What is presented to our mind as a result of all these separate occasions is that Florence Nightingale is the person who transformed nursing. Yet consider the person who transformed nursing and was an abolitionist for the politicisation of nursing. Both are referring to the same person, Florence Nightingale, but differ in their meaning insofar that one is referring to Florence Nightingale transforming nursing and the second is her opposition to the development of the national nursing register. This is what Husserl was indicating as the difference between the object intended and the object as it is intended ${ }^{[28]}$ and as such one must be distinguished from the other in order for the moment of perception to possess meaning.

\subsection{Phenomenological reduction}

Influenced in part by Descartes, Husserl viewed the reduction as a means to confirming epistemological assumptions about the nature of knowledge, especially how it is viewed within consciousness. Descartes' cogito certainly supported Husserl's thoughts about the bareness and pureness of consciousness whereas Descartes, using logical inference, took it one step further with ergo sum. Descartes was concerned with his perception of the world. He was not sure he could trust his senses or his reasoning; it was almost as if the world was a dream or worse being controlled by a demon. Yet, Descartes could indubitably trust in one thing - the fact that he doubted which he took to be a form of thinking and thus the cogito. This lead Husserl to consider consciousness (cogito) to be conscious of something. He wasn't interested in the ergo sum, because he believed being conscious also meant conscious experiences also had intentionality. ${ }^{[27]}$

How this is achieved, Husserl believed, is through a purging or cleansing of the mind to allow the essences of the phenomena to shine through. ${ }^{[29]}$ Aptly named the phenomenological reduction, this allowed Husserl to "go to the things

Published by Sciedu Press themselves", by bracketing the natural attitude to transcend subjective experience, theories, and suppositions in order to observe and describe the phenomena objectively - to identify the phenomenological essence. ${ }^{[24]}$ It is the essence that allows the researcher to be open to the full range of the conscious experience ${ }^{[30]}$ and thus, bracketing does not aim to change an individual's experience of the world, but to merely see it from a new light. ${ }^{[29]}$

It is here that the transcendental ego is able to engage in the purity of consciousness because, as mentioned above, the taken for granted experiences contained within the natural attitude have now become devoid of preconceived assumptions. ${ }^{[25]}$ Moreover:

“... it steps back to watch the forms of transcendence fly up like sparks from a fire; it slackens the intentional threads which attach us to the world and brings them to our notice."[31]

Using the example of a tree mentioned earlier, the reduction allows us to remove all preconceptions and beliefs associated with it - we "suspend our judgement about its metaphysical reality". ${ }^{[27]}$ The tree still exists, but it is now in a state of inexistence; our description of the tree is as it is experienced as opposed to our experience of the tree. The epoche/reduction allows the researcher to view how the experience of the tree presents itself to consciousness. But this is more than mere description. Husserl took this further by introducing imaginative free variation; a form of eidetic reduction, one in which the person uses their imagination to change various features of the phenomena, ${ }^{[27]}$ by refusing to accept the initial meaning of the phenomena. ${ }^{[32]}$ Therefore returning to the tree, in a simplistic way imaginative free variation asks us to try and imagine the 'treeness' of the tree as anything other than a tree - not its structure or form (its profile), but a variation on its characteristics, for example, its smell, its texture, its shape or its height. Those characteristics that cannot be changed without changing it from a tree are the tree's essences, it is the essences which the phenomenological reduction allows "the immediate and intuitive givenness to emerge as a conceptual theory" of the tree. ${ }^{[27]}$ As Zahari ${ }^{[24]}$ aptly describes it as:

\footnotetext{
“... looking for phenomena that can shake our ingrained assumptions and force us to refine, revise, or even abandon our habitual way of thinking."
}

Therefore, for Husserl, descriptions of the life-world not only aim to capture the raw essence of the phenomena or how the phenomenon was experienced, but take into consideration 
the nuances, the contextual underpinnings, the emotiveness, and the actions that were evoked in consciousness. Moreover, the phenomenological reduction resolves to suspend impressions, conceptions or beliefs surrounding the truth or accuracy of the phenomena in question. ${ }^{[32]}$

\section{Conclusion}

Husserlian descriptive phenomenology as a research method is widely used in the social sciences, one in which it aims to explore and describe the lived experience. However, un- derstanding the guiding features of phenomenology in the tradition of Husserl can be complex especially when deciphering how intentionality, the natural attitude and the phenomenological reduction are articulated into a research study. The aim of this paper was to explain these concepts by way of using practical examples of their use and supporting this with a discussion of how Husserl himself viewed descriptive phenomenology as a scientific research method.

\section{CONFliCtS OF INTEREST Disclosure}

The authors declare that there is no conflict of interest.

\section{REFERENCES}

[1] Klein P, Westcott MR. The changing character of phenomenological psychology. Canadian Psychology. 1994; 35(2): 133-158 https://doi.org/10.1037/0708-5591.35.2.133

[2] Moran D. Introduction to Phenomenology. Routledge, London: 2000. https://doi.org/10.4324/9780203196632

[3] Todres L, Holloway I. Descriptive phenomenology: life-world as evidence. In: Rapport, F. (2004), New Qualitative Methodologies in Health and Social Care Research. Routledge, London. 2004. 79-98 p. https://doi.org/10.4324/9780203408643_chapter_4

[4] Barnes J. The Complete Works of Aristotle: The Revised Oxford Translation. Oxford, Princeton University Press; 1984; 165-166 p.

[5] Sajama S, Kamppinen M. A historical introduction to phenomenology. London, Routledge. 2014.

[6] Baily A. Sextus Empiricus and Pyrrhonian Scepticism. Oxford University Press, Oxford. 2002. https://doi.org/10.1093/acpr of : oso/9780198238522.001.0001

[7] Frost G. Thomas Aquinas on the Perpetual Truth of Essential Propositions. History of Philosophy Quarterly. 2010; 27(3): 197-213.

[8] Marenbon J. Anslem: Prologion. In: Shand, J. Central Works of Philosophy Volume 1: Ancient and Medieval. Acumen, Chesham. 2005.

[9] Dowling M. From Husserl to van Manen. A review of different phenomenological approaches. International Journal of Nursing Studies. 2007; 44(1): 131-142. PMid:16412442 https://doi.org/10.1 016/j.ijnurstu.2005.11.026

[10] Glendinning S. In the name of phenomenology. Routledge, New York; 2007.

[11] Moran D. Intentionality: some lessons from the history of the problem from Brentano to the present. International Journal of Philosophical Studies. 2013; 21(3): 317-358. https://doi.org/10.1080/ 09672559.2013 .812605

[12] Fancher RE. Brentano's Psychology from an empirical standpoint and Freud's early Metapsychology. Journal of the History of the Behavioural Sciences. 1977; 13(3): 207-227. PMid:332759

[13] Morrison JC. Husserl and Brentano on Intentionality. Philosophy and Phenomenological Research. 1970; 31(1): 27-46. https ://doi.or $\mathrm{g} / 10.2307 / 2105978$

[14] Dahlberg K. Did Husserl change his mind? In: Ashworth, P.D., and Chung, M.C., Phenomenology and Psychological Science: Historical and Philosophical Perspectives. Springer, London: 2006. https://doi .org/10.1007/978-0-387-33762-3_5

[15] Dahlberg K, Drew N, Nystrom M. Reflective Lifeworld Research. Lund, Studentlitteratur. 2001.
[16] Bossert PJ. "Plato's Cave", flatland and phenomenology. In: Hamrick, W.S., ed (1985). Phenomenology in Practice and Theory. Springer, Netherlands. 1985.

[17] Hemberg K. Husserl's Phenomenology: knowledge, objectivity and others. London, Continuum International Publishing Group. 2006.

[18] Dreyfus HJ. Husserl's notion of noema. In Dreyfus, H.J., Hall, H., (1984). Husserl Intentionality and Cognitive Science. MIT Press, Cambridge. 1984.

[19] Luft S. Husserl's phenomenological discovery of the natural attitude. Continental Philosophy Review. 1998; 31(2): 153-170. https : //doi.org/10.1023/A:1010034512821

[20] Lubke P. A semantic interpretation of Husserl's epoche. Synthese. 1999; 118(1): 1-12. https://doi.org/10.1023/A: 1005101213 436

[21] Cerbone DR. Understanding Phenomenology. Acumen Publishing, Durham. 2006.

[22] Russell M. Husserl: a guide for the perplexed. New York, Continuum International Publishing Group. 2006.

[23] Crotty M. Phenomenology and Nursing Research. London, ChurchillLivingstone. 1996.

[24] Zahavi D. Husserl's Phenomenology. Stanford, Stanford University Press; 2003.

[25] Giorgi A. The descriptive phenomenological method in psychology: a modified Husserlian approach. Duquesne University Press, Pittsburgh. 2009.

[26] Olafson FA. Husserl's theory of intentionality in contemporary perspective. Nous. 1957; 9(1): 73-83. https://doi.org/10.2307/ 2214342

[27] Gallagher S. Phenomenology. London, Palgrave. 2012. https: //doi.org/10.1057/9781137283801

[28] Gurwitsch A. Husserl's theory of the intentionality of consciousness. In: Dreyfus, H., (1984). Husserl Intentionality and Cognitive Science. Bradford Books, Massachusetts. 1984. 59-71 p.

[29] LeVasseur J. The problem of bracketing in phenomenology. Qualitative Health Research. 2003; 13(3): 408-420. PMid:12669340 https://doi.org/10.1177/1049732302250337

[30] Stewart D, Mickunas A. Exploring Phenomenology: a guide to the field and its literature, 2nd ed. Athens, Ohio University Press; 1990.

[31] Merleau-Ponty M. Phenomenology of Perception. Routledge, London: 1962.

[32] Beech I. Bracketing in phenomenological research. Nurse Researcher. 1999; 6(3): 35-51. https://doi.org/10.7748/nr1999.04.6. $3.35 . c 6086$ 